\title{
To What Extent is the HDI a Good Indicator of the Relative 'Success' or 'Failure' of National Social Policies?
}

\author{
Melih Sever \\ Suleyman Demirel University Faculty of Finance and Administration, Department of Social Work \\ melihsever@sdu.edu.tr
}

\section{Doi:10.5901/ajis.2013.v2n8p208}

\section{Abstract}

The Human Development Index was launched in 1990. The idea was to measure development not just through income but also by looking at various indicators such as life expectancy and schooling. The HDI is not a good indicator of national social policies' success or failure. It suffers from many problems including; having fewer indicators to monitor for the sake of simplicity; poorly chosen indicators; methodological problems; calculation flaws and trade-off issues between variables. However, this does not change the fact that the index is, at the moment, is one of the most trustworthy and cited indexes in the field of development and it is welcomed by many governments and institutions around the world. Having said that, there are still more ways for us to develop more accurate and targeted, well grounded indexes to monitor the progress of countries in human development.

Keywords: Human Development, Social policy, HDI.

Human development is an idea, which encompasses improving the richness of human life, enlarging the choices of people and enhancing their wellbeing (UNDP, 1990 p. 10). For many years, human development was measured only by GDP (Gross Domestic Product) which is an economic indicator. When the UNDP realised that the economic growth itself does not necessarily create human development, the idea of the human development index (HDI) was developed (UNDP, 2011 p. 1).

The Human Development Index was launched in 1990. The idea was to measure development not just through income but also by looking at various indicators such as life expectancy and schooling. Since 1990, the index has been revised many times. The last index, which is 2011 at the time of writing this essay, was published in November 2011. The last index aims to monitor the progress of national social policies in three dimensions: health, education and living standards. Each dimension has different indicators. If we have a look at the indicators that the index employs, we can see that there are three main indicators that are newly revised by the UNDP. Life expectancy at birth is the indicator of the health component of the HDI. It takes 20 years as the minimum value and 83.4 years (Japan's life expectancy) as the maximum. If a country's life expectancy at birth is 75.2 (Vietnam), it is allocated a value 0.870 . If it is 83.4 (Japan), it gets 1.00 from the health component (UNDP, 2011 p. 168).

As for education, this is measured by two variables; the mean years of schooling for adults aged 25 and expected years of schooling for children of school entering age. It used to be measured by adult literacy rate, and enrolment rate into primary, secondary and tertiary schools (UNDP, 2011).

For living standards, the indicator is gross national income per capita. Again, this is a new indicator. The minimum income is $\$ 100$ and the maximum is $\$ 107,721$ (Qatar's income per capita in 2011). In the same way as health, each country is ranked and allocated a value from 0-1. The higher gross national income a country has, the nearer to 1 it gets.

Exploring the indicators, it can be seen that they are very simple and straightforward. However, there are debates and discussions concerning the method of the index. In this regard, two main issues will be discussed in this essay: first, the indicators that the index employs will be examined and evaluated. Secondly, the methodology that the index uses will be analysed in the light of the calculation system of the HDI values for each country. Since Stiglitz (2009) stated, "What you measure affects what you do", it is very significant to evaluate what and how an international body, which represents 193 countries around the world, measures in the name of human development (Forgeard, Jayawickreme and Seligman, 2011 p. 79).

This essay will argue that the HDI is not a good indicator of the relative success or failure of countries. What we mean by the HDI is not the Human Development Report, which monitors the progress of countries in many areas even in contraceptive prevalence rate and satisfaction with life (UNDP, 2011). Unlike the human development reports, the HDI 
itself lacks indicators in many areas of social policy such as political participation, social security and environmental issues. It also does not monitor moral development in anyway, which is one of the elements of human development (Basu, 2005 p. 3). Furthermore, the variables that the index uses are far from reflecting human development in a given country and the methodology of the index is highly debatable and causes concerns such as trade-off issue (Ravallion, 2010, p.7). Having said that, this essay will also argue that the HDI is one of the most comprehensive and reliable databases which monitors 187 countries and territories in the world at present on an annual basis (UNDP, 2011b).

In terms of the indicators, there have been considerable discussions about the appropriateness of the variables, which the index uses, even though the UNDP acknowledges that all criticisms are taken into account (Klugman, Rodriguez and Choi, 2011). It is obvious that choosing an indicator for the index is a challenging task. In order to introduce an indicator to the index the data has to be internationally comparable, reliable and regularly available since the index aims to monitor countries' progress over time (Raworth and Stewart, 2003 p. 141). First of all, excluding many variables from the index to make it more accurate and simple, prevents it from being comprehensive and reflective of human development. Secondly, some of the indicators are based on predictions about the future and they do not necessarily help us to understand current policies in a nation: rather they are the result of previous policies. Furthermore, as acknowledged by the UNDP, the index is not capable of monitoring short-term changes within a country. The reason for this is that two components of the HDI, namely life expectancy and mean years of schooling, are changing slowly.

For instance, the life expectancy indicator assumes that "...prevailing patterns of age-specific mortality rates at the time of birth will stay the same throughout the infant's life" (UNDP, 2011 p. 130). The number of years that the index estimates might be representative of the policies of the number of years before which affects the mortality rates at present. However, even if there is a strong relationship between the healthcare policies of a country and mortality rates, it does not necessarily mean that it is not affected by a war, epidemic or natural disaster.

Moreover, it could be argued that in order to get higher ranks in the index, one country could simply invest in an infant healthcare system and improve its rankings dramatically. In that case, it is only an infant care system that has been developed in that country not human development at all. Furthermore, I also argue that for countries that are experiencing internal war such as Turkey, it might be somehow problematic to address this issue without solving the war within the country. These numbers then do not necessarily display the efficiency of countries' social policies. Iraq and Sri Lanka are obviously going to have problems with the index due to war. Yet, the index tells that the life expectancy was 57.7 years in Iraq according to 2005 statistics right after the war with the U.S, whereas in the last report it was 69.0 years (UNDP, 2011 and 2008). It seems that the UN managed to obtain updated data from Iraq. However, how relevant these numbers are in the case of human development is again a matter of discussion.

As for the education dimension of the index, it has two indicators and one of them is expected years of schooling. As the name suggests, this is an estimation that the index makes by looking at the prevailing patterns of age-specific enrolment rates at the time of data gathering in each country (UNDP, 2011 p. 130). Therefore, we see the very same problem as the life expectancy here. The number of years of schooling therefore does not reflect current policies. Furthermore, countries like Turkey, can make efforts to improve the mean years of schooling by increasing the years of compulsory education but not the quality of it. In that case, we see Turkey has higher rankings due to an increase in the education indicator of the index but the outcome of the years spent in classes could be overlooked. Hence, knowing the number of years people spend in education says little about human development. Moreover, the main purpose of education should be something, other than keeping children within school buildings. For this reason, many international organisations around the world who deal with the education sector aim not to increase the time that people spend in education institutes but to increase the quality of education and to equip people with the necessary skills for life (The World Bank, 2011).

The problem of substitutability is also widely discussed in academic circles (Ravallion, 2010 and Desai, 1991). Any nation who wishes to maximise its ranking in the HDI can focus solely on one indicator either education or life expectancy, (GNI would be the hardest one to improve I suppose), and disregard the others. Even though the UNDP states that "we should not let changes in any of the dimensions go unnoticed" (UNDP, 2010 p.15), Ravallion argues that this might not be the case. He goes on to say that it is not at all clear how the index, by switching the calculation of the $\mathrm{HDI}$ values from the arithmetic mean to the geometric mean, makes poor performances in any dimension get noticed (Ravallion, 2010 p. 6).

As for the indicator of a decent standard of living as the index named it, GNI (Gross National Income per capita) replaced GDP in the 2010 report. The rationale behind this change is that GDP does not include transfers from other countries that people receive, such as remittances, whereas GNI includes them (Klugman, Rodriguez and Choi, $2011 \mathrm{p}$. 20). However, it may well be argued that there is a little need to include an economic indicator in an index, which stresses 
the importance of human development. Moreover, GNI or GDP plays a very small role in human development or happiness or in expanding capabilities where most of the population of a nation live in high living standards and above material needs (Helliwell, Layard and Sachs, 2012 p. 91 and Klugman, Rodriguez and Choi, 2011 p. 30).

As far as the decent standard of living dimension of the index is concerned, it is also worth mentioning that the index shows insightful data about the countries which have a higher GNI per capita but low human development compared to the countries which have low economic values but a higher HDI value in total. For instance, Yemen has \$2.213 GNI per capita and ranks 154 in the HDI index, whereas Madagascar has \$824 GNI per capita and ranks 151 in the HDI (UNDP, 2011a). The gap between the two countries can be informative. By exposing these kinds of cases, the UN actually does put pressure on these countries who have problems of transparency in money spending, and draw the issue to the attention of international communities.

As for the second main issue, which is the methodology of the index, setting maximum and minimum values for each dimension of the index seems to have the potential to cause debates. At the moment, the index sets a maximum value according to the highest observed values in the time span (1980-2011) and those countries that have lower values score lower on each dimension. It seems very illegitimate that a country like Qatar should receive the full score of 1.00 in the income dimension whilst countries like Sweden or Scandinavian countries which are often shown as model welfare systems (Andersen, 2007 p. 2) receive lower score as their income is not $\$ 107.721$. Does this really say anything about their human development?

Instead of using GNI for each country, a minimum amount of income per capita for good living standards can be calculated for each country according to their own circumstances. For instance, Turkish civil organisations calculate the minimum amount of money to live in a decent standard for a family of four for one month as approximately $£ 1000$ in Turkey (Turk-Is, 2012). As long as countries can provide this minimum amount to its citizens and regardless of how much more they can have, they should score 1.00 full point whereas for countries which cannot provide the fixed amount for any given year, the index should give a value less than 1.00 based on how poorly paid people are in that country. Therefore, the total HDI value would decrease. This would decrease the importance of income and make the index more human development centric. However, going into the technical details of estimation or aggregation of this proposed indicator exceeds our limits in this paper. Yet, having this kind of economic indicator may make more sense to those who are not convinced with the significance of economic indicators in a human development index.

In terms of the education dimension of the index, the observed maximum value of mean years of schooling is 13.1 (Czech Republic's mean) and it is 18.0 for expected years of schooling in the HDI 2011. The more a country educates its citizens, the more they score in the HDI no matter how they achieve that. Is that what theUN wants in countries like Kyrgyzstan, in which 9 years compulsory education policy is implemented and it scores one of the lowest in the PISA (OECD, 2010) evaluation? Moreover, 1/3 of the students in Kyrgyzstan do not even have basic reading skills, yet it has 9.3 years schooling in the HDI with 0.71 mean years of schooling index. On the other hand, even though Singapore has one of the lowest mean years of schooling scores (8.8) amongst very high human development countries and lower than Kyrgyzstan in the HDI 2011, the students in Singapore are the 5th highest performing in the PISA 2009 results (OECD, 2010 p. 52 and 13, and UNDP, 2011 p. 127-129). There seems to be a legitimate compatibility problem between the purpose of the index and what the index measures in the education dimension. If the expected outcome of the education process is not to equip people with basic reading and mathematic skills, then there is no problem with measuring the years spent in education. However, as the index implicitly advocates if not explicitly, increasing the years in education should not be ultimate goal of education policies around the world. Nevertheless, some countries seem to be practicing UNDP's recommendations about schooling.

For example in Turkey, compulsory education was raised to 12 years recently without the necessary infrastructure and skilled professionals (MEB, 2012). Even though this does not prove that Turkish education policy is inspired by the $\mathrm{HDI}$, it may well be argued that it may have been influenced by the HDI approach.

In terms of the weighting of dimensions in the index, it may be argued that although UNDP made it clear that the idea of giving equal weights is not an accident, it is still not convincing. The report suffices by saying that giving equal weights to each dimension shows their equal importance in human development. However, without giving any explanation and logic behind it, this choice seems random. Some even claim that it is arbitrary to give equal weights to the indicators without a legitimate rational (Chowdhury and Squire, 2006 p. 761).

Furthermore, the level of criticism arises in academia at times when academics find this kind of index misleading. Hoyland, Moene and Willumsen (2012 p. 10) argue that the HDI should classify countries into groups instead of ranking them on the grounds that the findings are uncertain and imaginary. An index like the HDI which ranks countries can be deceptive "... not because of wrong indicators, but because the estimation of the scores inherent uncertainty" (Hoyland, 
Moene and Willumsen, 2012 p. 10).

Although the HDI has attracted many criticisms from a wide range of followers including the Rwandan government (2011), it still deserves attention. According to Klugman (2011), the HDI is more searched on Google than its competitor the World Bank's World Development Report (WDR). In terms of academic citations, 4470 articles cited the HDR as oppose to the WDR, which was, cited 3020 times (Klugman, Rodriguez and Choi, 2011 p. 1). Moreover, it revises itself constantly. The reports, which are written by UNDP staff, are informative and enlightening. One of the main advantages of the index is that it comprises excessive international data, which are collected through reliable means so that all countries with few exceptions can be compared. More importantly, it challenged the hegemony of GDP based measurements. Many believe now that the HDI is a much better measurement than GDP, even though it is not perfect (The New York Times, 2010).

In conclusion, The HDI is not a good indicator of national social policies' success or failure. It suffers from many problems including; having fewer indicators to monitor for the sake of simplicity; poorly chosen indicators; methodological problems; calculation flaws and trade-off issues between variables. However, this does not change the fact that the index is, at the moment, is one of the most trustworthy and cited indexes in the field of development and it is welcomed by many governments and institutions around the world. Having said that, there are still more ways for us to develop more accurate and targeted, well grounded indexes to monitor the progress of countries in human development.

\section{References}

Andersen, M. T. (2007) 'The Scandinavian Model-Prospects and Challenges', Cesifo Working Paper, No: 1903.

Basu, L., R. (2005) 'Why the Human Development Index does not measure up to ancient Indian standards', Culture Mandala: The Bulletin of the Centre for East-West Cultural and Economic Studies, 6: (2), 5.

Chowdhury, S. and Squire, L. (2006) 'Setting Weights for Aggregate Indices: An Application to the Commitment to Development Index and Human Development Index', Journal of Development Studies, 42 (5): 761-771.

Desai, M. J. (1991). 'Human Development: Concepts and Measurement' European Economic Review 35(2/3): 350-357.

Forgeard, M. J. C., Jayawickreme, E., Kern, M. \& Seligman, M. E. P. (2011). Doing the right thing: Measuring wellbeing for public policy. International Journal of Wellbeing, 1(1), 79-106. doi:10.5502/ijw.v1i1.15.

Helliwell, J., Layard, R. and Sachs, J. (2012) World Happiness Report, Earth Institute: Columbia University.

Hoyland, B., Moene, K., and Willumsen, F. (2012) 'The Tyranny of International Index Rankings', Journal of Development Economics, 97: 1-14.

Klugman, J., Rodriguez, F. and Choi, H. (2011) 'Human Development Research Paper 2011/01', The HDI 2010: New Controversies, Old Critiques, New York: UNDP.

MEB (Milli Egitim Bakanligi), (2012) '12 Yıllık Zorunlu Eğitime Yönelik Uygulamalar', Genelge 2012/20, http://www.meb.gov.tr/haberler/ 2012/12YillikZorunluEgitimeYonelikGenelge.pdf.

OECD, (2010) PISA 2009 Results: What Students Know and Can Do - Student Performance in Reading, Mathematics and Science (Volume I),http://dx.doi.org/10.1787/9789264091450-en.

Ravallion, M. (2010b) 'Troubling Tradeoffs in the Human development Index', Policy Research Working Paper 5484, Washington DC: The World Bank.

Raworth, K. and Stewart, D. (2003) 'Critiques of the Human Development Index', Readings in Human Development, 2.4: 140-152.

Republic of Rwanda, (2011) 'Outdated and misleading data in HDR 2011, Ministry of Finance and Economic Planning', http://www.minecofin.gov.rw/node/417.

The World Bank, (2011) Learning for All Investing in People's Knowledge and Skills to Promote Development, Washington: World Bank.

Turk-Is, (2012) 'Nisan 2012 Aclik ve Yoksulluk Siniri' Turk-Is Haber Bulteni: 27/04/2012.

UNDP, (2011a) 'Human Development Index (HDI)', accessed 14/05/2012. http://hdr.undp.org/en/statistics/hdi/.

UNDP (2011) Human Development Report Sustainability and Equity: A Better Future for All, New York: Macmillan.

UNDP, (2011b) 'Frequently Asked Questions (FAQs) about the Human Development Index (HDI)', http://hdr.undp.org/en/media/ FAQS_2011_HDI.pdf.

UNDP, (1990) Human Development Report, New York: Oxford University Press.

UNDP, (2008) Human Development Report 2007/2008 Fighting Climate Change: Human Solidarity in a Divided World, New York: UNDP. 